\title{
Activities-Specific Balance Confidence in People with Multiple Sclerosis
}

\author{
Ylva Nilsagård, ${ }^{1,2}$ Anna Carling, ${ }^{1,3}$ and Anette Forsberg ${ }^{4}$ \\ ${ }^{1}$ Centre for Health Care Sciences, Örebro County Council, P.O. Box 1324, 70113 Örebro, Sweden \\ ${ }^{2}$ School of Health and Medical Sciences, Örebro University, Sweden \\ ${ }^{3}$ Department of Physiotherapy, Örebro University Hospital, 70185 Örebro, Sweden \\ ${ }^{4}$ Family Medicine Research Centre, Örebro County Council, P.O. Box 1613, 70116 Örebro, Sweden \\ Correspondence should be addressed to Ylva Nilsagård, ylva.nilsagard@orebroll.se
}

Received 30 March 2012; Revised 25 June 2012; Accepted 25 June 2012

Academic Editor: W. Bruck

Copyright (C) 2012 Ylva Nilsagård et al. This is an open access article distributed under the Creative Commons Attribution License, which permits unrestricted use, distribution, and reproduction in any medium, provided the original work is properly cited.

Objective. To evaluate the validity of the Activities-specific Balance Confidence scale (ABC) in people with multiple sclerosis (PwMS). Design. A multicentre, cross-sectional study. Setting. Six rural and urban Swedish sites, including specialized units at hospitals and primary care centers. Participants. A sample of 84 PwMS with subjective gait and balance impairment but still able to walk $100 \mathrm{~m}$ (comparable with EDSS 1-6). Outcome Measures. Timed Up and Go, Timed Up and Go ${ }^{\operatorname{cog}}$, 25-foot Timed Walk Test, Four Square Step Test, Dynamic Gait Index, Chair Stand Test, 12-item MS Walking Scale, self-reported falls, and use of assistive walking device were used for validation. Results. The concurrent convergent validity was moderate to good $(0.50$ to -0.75$)$ with the highest correlation found for the 12-item MS Walking Scale. The ABC discriminated between multiple fallers and nonfallers but not between men and women. Ecological validity is suggested since ABC discriminated between users of assistive walking device and nonusers. The internal consistency was high at $\alpha=0.95$, and interitem correlations were between 0.30 and 0.83 . Conclusion. This study supports the validity of the ABC for persons with mild-to-moderate MS. The participants lacked balance confidence in many everyday activities, likely restricting their participation in society.

\section{Introduction}

Multiple sclerosis (MS) is the most common progressive neurological disease among younger adults, with approximately 17000 people diagnosed in Sweden in 2011 [1] and an estimated 2.5 million people with MS (PwMS) worldwide [2]. More women than men are diagnosed as having MS; the ratio is at least 2:1 [3]. Balance impairments are common [4], and knowledge of the underlying causes is increasing [5]. Imbalance is reported as an initial symptom [6] and is present in minimally impaired PwMS [7] and even in clinically isolated syndrome suggestive of MS [8]. Imbalance increases the risk of falls; the prevalence of falls has been reported as being between $48 \%$ (EDSS not reported; eligibility criteria: able to walk independently or with a can, without relevant cognitive and orthopedic impairments) and 63\% (EDSS 3.5-6.0) [9-12]. There is no consensus regarding differences in the risk of falls between men and women with
MS. Finlayson et al. reported that men have a greater fall risk than women [10], but a study of 76 PwMS did not confirm this result [12].

The complexity of imbalance can be explained by the multiplicity of control systems involved [13]. The actual performance of balance-demanding activities also includes a psychological component. Studies investigating the psychological aspects of imbalance in PwMS have primarily used the concept "fear of falling" $[14,15]$, which is defined as a lasting concern about falling that can lead to curtailed activity [16]. Self-efficacy is defined as a person's confidence in being able to perform a given task. High self-efficacy increases the chance of succeeding in performing an activity, regardless of actual physical ability $[17,18]$. PwMS who report fear of falling have been shown to have a greater risk for falls [10], and being concerned about falling is common in PwMS, whether or not they have recently experienced a fall [19]. A majority of those who were concerned about falling also 
reported having limited their activity as a consequence of their concern. If a person is not confident in maintaining their balance, they are unlikely to actually perform activities within their capacity. Strengthening the patient's confidence is just as important as improving function, and it is essential for caregivers to be aware of how confident a person is in managing different activities. It is possible to strengthen a person's balance confidence via interventions [20].

One measure of balance confidence is the Activitiesspecific Balance Confidence (ABC) Scale. The ABC scale was initially designed for elderly people, as a development of the Falls Efficacy Scale [21] and has captured interest worldwide and has been translated into several languages [22-30], and some cultural adaptations have been made. Besides cultural aspects, environmental aspects as climate must be considered when applying the scale.

It is possible that men and women differ in terms of balance confidence, but the evidence is inconclusive. In a sample of older adults $(n=475)$, men scored significantly higher balance confidence than women $(P<.002)$ [31], while in another sample $(n=60)$, no gender difference was found [32]. Middle-aged and older women with MS are more likely to report fear of falling than men with MS [14] when investigated with an interview question (yes/no). It has not yet been shown whether or not this result can be generalized to other samples of PwMS.

The ABC scale has been used for PwMS and validated once $(n=51)$ using an Italian translation [28]. Convergent validity for the clinically assessed measures was $r=0.54$ for the Dynamic Gait Index (DGI), $r=0.48$ for the Berg Balance Scale (BBS), and $r=-.38$ for the Timed Up and Go test (TUG). The ABC discriminated between fallers and non-fallers and was slightly better at identifying nonfallers $($ specificity $=77 \%)$ than fallers (sensitivity $=74 \%$ ). Retrospective falls only one month before the assessment procedure were used to define a faller, and people with primary progressive MS was excluded. No analyses were reported for potential differences between men and women. The validity of $\mathrm{ABC}$ for PwMS seems promising, but the results need to be verified in larger samples also including people with primary progressive MS and in different settings. Extending the period for self-reported falls may give a more reliable result. In the present study, a Swedish sample with mild-to-moderate MS was used, and falls were reported for two months.

There is no gold standard for measuring balance confidence. In the present study, the TUG and the DGI were included to allow comparison of the results with the work by Cattaneo et al. [28]. Additional outcome measures were also used, reflecting gait speed, dual tasks, stepping in different directions, the time taken to repeatedly rise to standing and sit down again, and perceived limitation of walking due to MS. The hypothesis was that the concurrent convergent and interitem validity would be moderate to good and that the $\mathrm{ABC}$ could discriminate for fallers and users of assistive walking device but not for gender.

The aim of this study was to evaluate concurrent convergent validity, discriminative validity, interitem validity, and internal consistency of the ABC of people with mild-tomoderate MS.

\section{Methods}

2.1. Design. A multicentre, cross-sectional data collection was conducted from September 2010 to June 2011 at six sites from both rural and urban areas in Sweden representing four county councils (Örebro, Sörmland, Värmland, and Västmanland).

2.2. Participants. The study included data from 84 persons with mild-to-moderate MS diagnosed according to the McDonald criteria [33]. Data were obtained from the first measure point in a randomized controlled trial evaluating balance exercise [34]. The inclusion criteria were selfperceived impaired gait and balance ability in standing and walking activities, and remaining ability to walk at least $100 \mathrm{~m}$ without rest but with the use of assistive device if needed (comparable with EDSS 1-6). The exclusion criteria were inability to understand the instructions or fill in the rating scales, ongoing exacerbation affecting balance, or other disease preventing them from performing the measurements. The study followed the Helsinki declaration and was approved by the Regional Ethics Committee (Dnr 2010/263).

2.3. Procedure. Data were collected at one time point at the respective departments of physiotherapy by physiotherapists trained in securing according to test protocol. The tests were performed in a standardized order as described below. The physiotherapist was present and available for questions when the rating scales were filled in.

2.4. Outcome Measures. The $\mathrm{ABC}$ scale measures balance confidence while performing 16 different activities [35] incorporating static, dynamic, proactive, and reactive balance [36].

The Timed Up and Go test (TUG) is a commonly used instrument which measures the time taken to rise from a chair, walk $3 \mathrm{~m}$, turn, walk back, and sit down again [37]. It is valid [28] and reliable for PwMS, and one measurement is sufficient [38]. In the present study, the participants were encouraged to walk safely but as quickly as possible. One practice attempt was allowed before the actual testing.

The TUG ${ }^{\text {cognitive }}$ is performed by adding a cognitive component to the TUG (backward counting in multiples of three) [39]. Those reporting falls tend to take longer on this test compared to non-fallers [12]. One attempt was recorded.

The 25-foot timed walk test (25TWT) measures walking speed [40]. The 25TWT is part of the MS Functional Composite disability assessment and is considered valid and reliable for PwMS also as an individual test [40-42]. The test was repeated twice, and the mean value was used in further calculations.

The Dynamic Gait Index (DGI) consists of eight walking items involving actions such as changing speed, moving one's head, turning, stepping over or walking around obstacles, 
and climbing stairs [36]. Performance on each item is rated between 0 and 3 by the physiotherapist, with a higher score indicating better performance. The DGI is valid, and the interrater reliability is good when used among PwMS [43].

The Four Square Step test (FSST) measures the ability to step over four $2.5 \mathrm{~cm}$ height sticks (forwards, sideways, backwards, and sideways) first clockwise and then back again, while facing forwards [44]. It was originally designed for older people but has also been used for PwMS [12].

The Chair Stand Test (CST) is a measure of functional strength and balance in which the time is registered for a sequence of 10 sit-to-stands from a chair [45]. The use of armrests was allowed.

Fall was reported retrospectively for two months prior to data collection and was defined as an unexpected contact of any part of the body with the ground. Falls were categorized as no fall, one fall, or two or more falls (multiple) falls. Data on assistive walking device indoors and outdoors was collected.

2.5. Statistical Procedure. Nonparametric methods were used due to data distribution. Concurrent convergent validity between the $\mathrm{ABC}$ scale and the other measures and interitem correlation were estimated using Spearman's rho. Internal consistency was estimated using Cronbach's alpha. Differences between men/women, single or multiple fallers/nonfallers, and use of assistive walking device or not were calculated using the Mann-Whitney $U$-test (two-tailed). The significance level was set at $P \leq 0.05$.

\section{Results}

Sixty-four $(76 \%)$ of the 84 participants were women, 31 $(37 \%)$ had fallen at least once during the two months before data collection, and 41 (49\%) used assistive device outdoors (Table 1).

All items in the $A B C$ were filled in by all participants. One person failed to perform the TUG ${ }^{\text {cognitive }}$ due to language difficulties that became apparent only in the stressful test situation. Two persons failed to perform the Four Square Step test due to the need to use rolling walker.

The median score for the ABC was 66 (IQR 45-80) for the total sample (Figure 1). A wide variation of ratings was present for the items. There were floor and ceiling effects for each $A B C$ item except item 1 "walk around the house" (min 10: $\max 100$ ) but not for the ABC score (min 23.1; $\max 96.88$ ). The most challenging activities were standing on a chair and reaching for something, stepping onto or off an escalator without hand support, and walking on icy sidewalks. The items most frequently rated with "complete confidence" were walking around the house, reaching for a small can on a shelf at eye level, sweeping the floor, walking outside the house to a car parked in the driveway, getting into and out of a car, and walking across a parking lot to the mall. Still, only one-third of the sample felt completely confident for each of these activities individually.

The internal consistency was high at $\alpha=0.95$. The separate items ranged from 0.64 (item 9) to 0.81 (item 10).
Cronbach's alpha did not change if item 9 "getting in or out of a car" was removed, suggesting that this item adds little value. The interitem correlations presented a median correlation at 0.60 (IQR 0.52-0.66). The highest interitem correlation (0.83) was found between the two activities connected with the lowest rated balance confidence (walk on icy sidewalks; step onto or off an escalator without hand support) (Table 2). No specific patterns were found by grouping the items as mainly reflecting anticipatory postural adjustments (stairs, ramp, escalator and icy sidewalks), postural responses (being bumped into, walk on icy sidewalks) or as stability limits/verticality (bending, reaching). The interitem correlations were not higher by grouping items as indoor or outdoor activities.

The fallers ( $\geq 1$ fall) performed worse than the nonfallers for all outcome measures with the exception of TUG ${ }^{\text {cog }}$ (Table 3).

As hypothesized, the concurrent convergent validity was overall moderate to good ( 0.50 to -0.75 ; Table 4$)$, with the lowest correlation found for the TUG ${ }^{\mathrm{cog}}$ and the highest for the MSWS-12. There were no statistically significant differences in balance confidence using the $A B C$ between those reporting one or more falls during the two months prior to the testing procedure compared to those reporting no falls. Median score was 68 (IQR 53-84) among fallers ( $\geq$ fall) and 64 (IQR 40-75) among non-fallers, giving a difference in $\mathrm{ABC}$ total score of only 4 points. However, a significant difference $(P \leq 0.02)$ was found between nonfallers and the multiple fallers (median $\mathrm{ABC}$ score 48; IQR 38-69). A statistically significant difference at $P \leq 0.001$ was also found in $\mathrm{ABC}$ scoring between those reporting using assistive device outdoors or not. Lower balance confidence was reported by users (median score 56; IQR 38-68) compared to nonusers (median score 74; IQR 64-88).

There were no statistically significant differences between men and women for the ABC score $(P=0.77)$. The median score was 67 (IQR 47-75) for men and 66 (IQR 45-83) for women. Statistical differences between men and women were also absent for the other outcome measures.

\section{Discussion}

The validity of the $A B C$ when used on PwMS was further strengthened in the present study. The concurrent convergent validity between the $\mathrm{ABC}$ and the other outcome measures was moderate to good, as hypothesized, and the internal consistency remained high at $\alpha=0.95$. Balance confidence is clearly related to balance function although the concepts differ somewhat. Higher correlations were found in the present study for both the Dynamic Gait Index $(r$ $=0.62)$ and Timed Up and Go $(r=-0.61)$, compared to those previously reported for PwMS ( $r=0.54$ and $r=-0.38$, resp.) in an Italian sample $(n=51)$ [28]. Perceptions of limitations in walking and balance confidence were closely related. Both the ABC and the 12-item MS Walking Scale are self-rating scales and incorporate standing and walking activities though the 12-item MS Walking Scale is focused on 
TABLE 1: Demographic data. Medians and interquartile ranges (25-75\%) presented for age and time since diagnose, mean for walking speed, otherwise frequency and percentage.

\begin{tabular}{|c|c|c|c|c|c|}
\hline Variable & $\begin{array}{c}\text { Total } \\
n=84\end{array}$ & $\begin{array}{c}\text { Women } \\
n=64\end{array}$ & $\begin{array}{c}\text { Men } \\
n=20\end{array}$ & $\begin{array}{c}\text { Faller } \geq 1 \\
n=31\end{array}$ & $\begin{array}{c}\text { Nonfaller } \\
n=53\end{array}$ \\
\hline Faller & $31(37)$ & $20(45)$ & $11(55)$ & - & - \\
\hline Age & $51(42-58)$ & $49(42-58)$ & $55(38-60)$ & $53(45-60)$ & $\begin{array}{c}48 \\
(40-58)\end{array}$ \\
\hline Time since diagnose & $12(6-18)$ & $12(7-18)$ & $12(2-18)$ & $12(6-19)$ & $10(6-17)$ \\
\hline Walking speed (m/s) & 1.17 & 1.13 & 1.30 & 1.11 & 1.21 \\
\hline \multicolumn{6}{|l|}{ MS type } \\
\hline $\mathrm{RR}$ & $54(64)$ & $44(69)$ & $10(50)$ & $19(61)$ & $35(66)$ \\
\hline SP & $26(31)$ & $19(30)$ & $7(35)$ & $10(32)$ & $16(30)$ \\
\hline $\mathrm{PP}$ & $4(5)$ & $1(2)$ & $3(15)$ & $2(6)$ & $2(4)$ \\
\hline \multicolumn{6}{|l|}{ Walking device } \\
\hline indoors & $15(18)$ & $11(17)$ & $4(20)$ & $8(26)$ & $7(13)$ \\
\hline outdoors & $41(49)$ & $32(50)$ & $9(45)$ & $21(68)$ & $20(38)$ \\
\hline Work/study & $47(66)$ & $35(65)$ & $12(75)$ & $16(52)$ & $31(58)$ \\
\hline
\end{tabular}

RR: relapsing remitting; SP: secondary progressive; PP: primary progressive.

Median values for $\mathrm{ABC}$ scoring for the total sample $(n=84)$

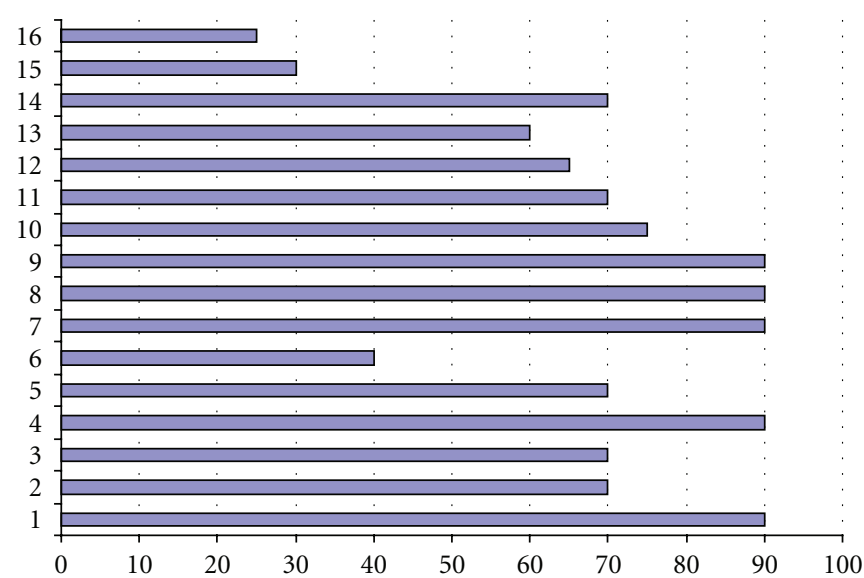

Figure 1: 1 walk around the house, 2 walk up and down stairs, 3 bend over and pick up a slipper from the front of a closet floor, 4 reach for a small can off a shelf at eye level, 5 stand on your tip toes and reach for something above your head, 6 stand on a chair and reach for something, 7 sweep the floor, 8 walk outside the house to a car parked in the driveway, 9 get into or out of a car, 10 walk across a parking lot to the mall, 11 walk up and down a ramp, 12 walk in a crowded mall where people rapidly walk past you, 13 are bumped into by people as you walk through the mall, 14 step onto or off an escalator while holding onto a railing, 15 step onto or off an escalator while holding onto parcels, and 16 walk on icy sidewalks.

limitations in walking rather than balance confidence during activities.

The inclusion of both fallers and non-fallers is a strength when validating balance confidence. Those reporting one fall the past two months and non-fallers showed no difference in balance confidence according to the $\mathrm{ABC}$, contradicting previous results where fallers scored on average 24 points lower than non-fallers [28]. In that study, the non-fallers scored a mean of 61 , while in the present study they scored a median of 68 and a mean of 66, though the samples otherwise seem comparable in many ways. The fallers in the present study were somewhat older and used walking devices more frequently both indoors and outdoors, compared to the non-fallers. However, the $\mathrm{ABC}$ was able to statistically significantly discriminate between those reporting two falls or more and non-fallers. Furthermore, the ABC discriminated between those reported who need to use assistive walking device outdoors and nonusers, and the need to use walking device presumably reflects a more pronounced disability. Both the use of assistive walking device and a higher impact of MS have been reported to be associated with falling. The instructions of the $\mathrm{ABC}$ reads that if a person normally uses walking device or support, the items should be rated as if one were using this. Still, the use of assistive walking device does 


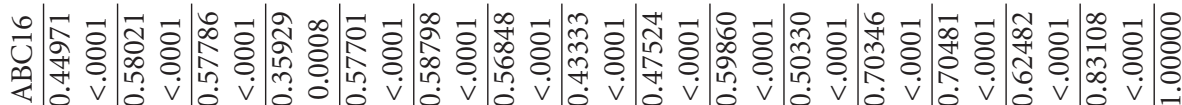

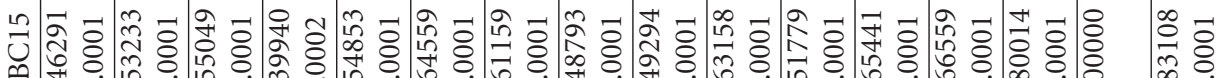

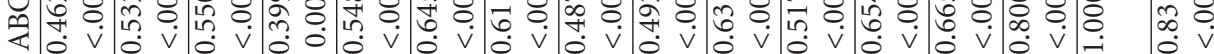

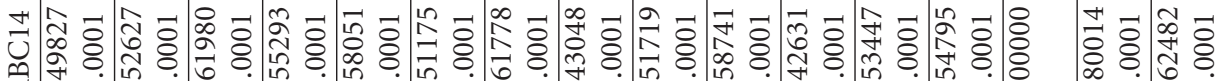

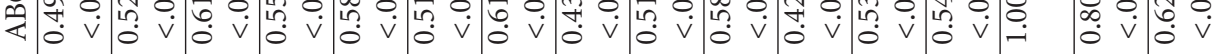

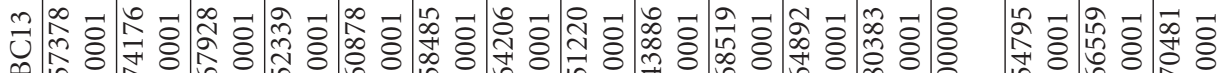

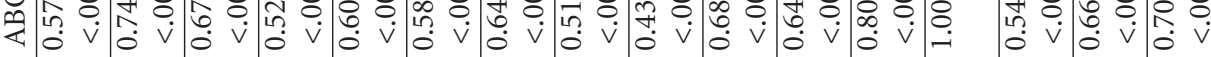

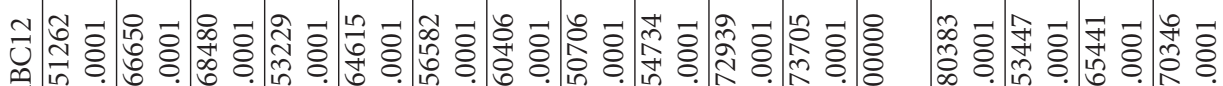

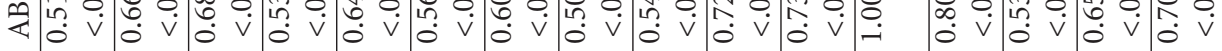

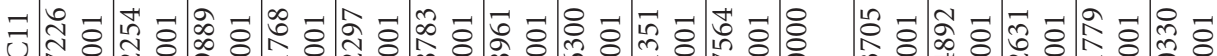

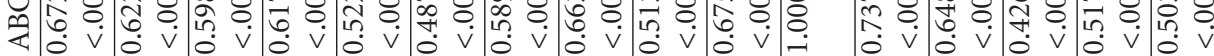

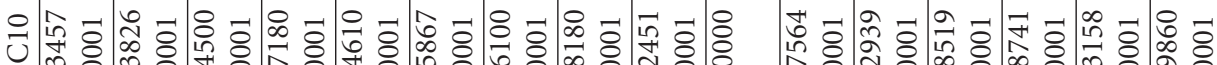

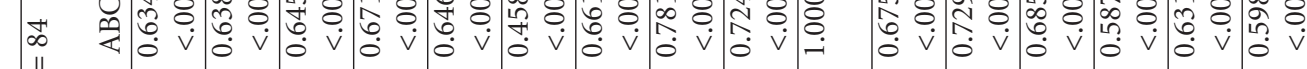

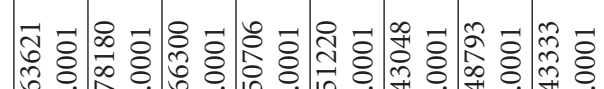

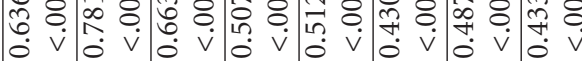

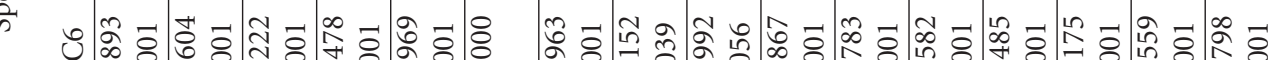

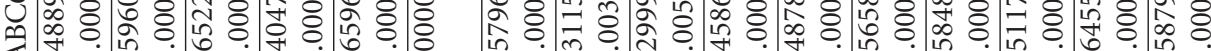

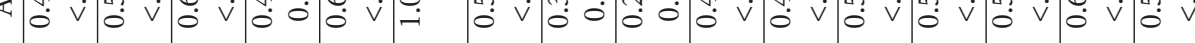

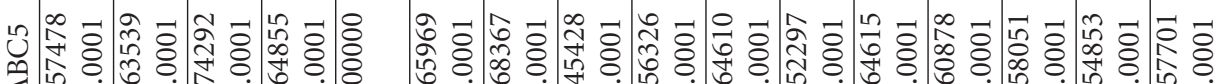

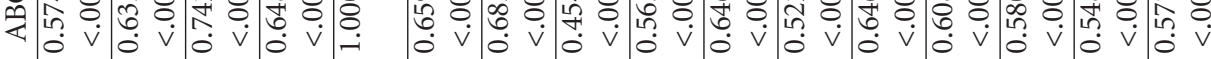

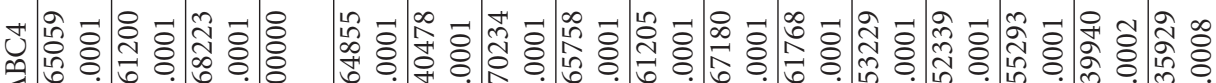

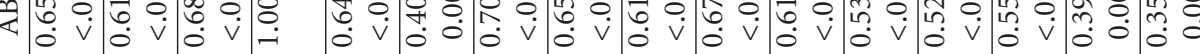

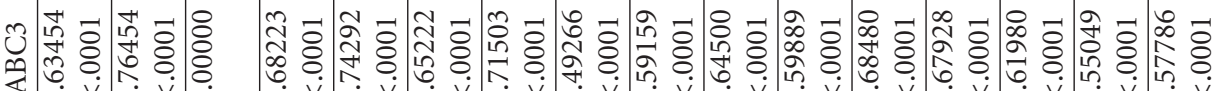

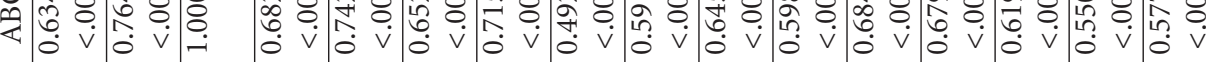

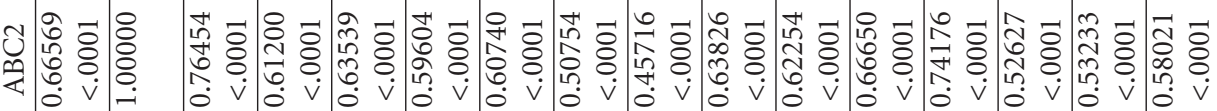

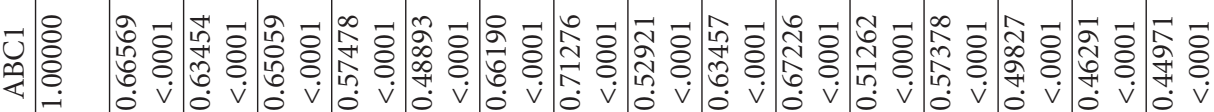
ర

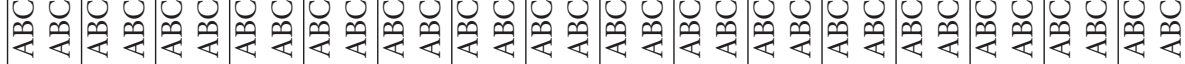


TABLE 3: Mean and SD of the outcome measures for the total sample and the subgroups non-fallers and fallers.

\begin{tabular}{lcccccc}
\hline & \multicolumn{2}{c}{ Total } & \multicolumn{2}{c}{ Fallers $(\geq 1)$} & \multicolumn{2}{c}{ Nonfallers } \\
& \multicolumn{2}{c}{$n=84$} & \multicolumn{2}{c}{$n=31$} & \multicolumn{2}{c}{$n=53$} \\
& Mean & SD & Mean & SD & Mean & SD \\
\hline TUG & 11.83 & 6.02 & 12.52 & 5.57 & 11.43 & 6.28 \\
TUG $^{\operatorname{cog}}(n=83)$ & 14.32 & 7.07 & 13.94 & 4.91 & 14.53 & 8.08 \\
25TW & 6.51 & 3.24 & 6.85 & 2.67 & 6.32 & 3.55 \\
FSST $(n=82)$ & 17.29 & 13.00 & 18.18 & 12.34 & 16.74 & 13.47 \\
DGI & 17.08 & 4.62 & 15.06 & 3.98 & 18.26 & 4.60 \\
CST & 34.11 & 11.35 & 38.20 & 12.59 & 31.71 & 9.91 \\
MSWS-12 & 51.44 & 25.26 & 59.61 & 20.40 & 46.66 & 26.75 \\
ABC & 63.74 & 20.42 & 59.78 & 64.38 & 66.06 & 20.75 \\
\hline
\end{tabular}

TABLE 4: Convergent validity between the $\mathrm{ABC}$ and the other tests, $n=84$ unless other reported.

\begin{tabular}{lcc}
\hline Variable & $\begin{array}{c}\text { Correlation } \\
\text { coefficient }\end{array}$ & $P$ value \\
\hline Timed Up and Go test & -0.61 & $<.0001$ \\
Timed Up and Go ${ }^{\text {cognitive }}$ test $(n=83)$ & -0.50 & $<.0001$ \\
Timed 25-foot walk test & -0.63 & $<.0001$ \\
Four Square Step test $(n=82)$ & -0.59 & $<.0001$ \\
Dynamic Gait Index & 0.62 & $<.0001$ \\
Timed Chair Stand test & -0.61 & $<.0001$ \\
12-item MS Walking Scale & -0.75 & $<.0001$ \\
\hline
\end{tabular}

not seem to fully compensate for the mobility impairment since balance confidence remains reported as more limited. The transfer of having limited balance confidence to the use of walking device may be considered as ecological validity of the $\mathrm{ABC}$.

Balance confidence did, as expected, not differ between men and women. Men and women did differ in terms of age (men: 55 years, IQR 38-60; women: 49 years, IQR 42-58), which may have interfered with the comparison. These results differ from those reported by Peterson et al. [14] and is most likely explained by their use of an older sample of PwMS (mean age 63.6; SD = 9.3.). Future, larger studies could investigate both possible gender differences in balance confidence and any gender dependence for different activities.

One strength of the $\mathrm{ABC}$ is that it incorporates everyday activities both indoors and outdoors. It is notable that even activities such as walking around the house, reaching, and sweeping were considered challenging by two-thirds of the sample, especially since $56 \%$ of the participants were currently working or studying. The restrictions on participation in society are clear, given that two-thirds of the PwMS in this study were not completely confident in being able to walk across a parking lot and get into or out of a car. Walking on icy sidewalks is both geographically and seasonally dependent. The instructions for the $\mathrm{ABC}$ state that if you have not performed the activity recently, you should imagine how confident you would be if performing it. The disadvantage of this is that it may be difficult to rate the actual ability, due to the length of time since last having performed the activity and the progressive path of MS.

The internal validity of the study was strengthened by using physiotherapists who had received suitable training to acquaint them with the test procedure and standardized protocols. The physical tests were performed before the selfrating procedure, which may have affected the participants' perception, but none of the rated items were identical to the physical outcome measures. Perception of one's ability to perform an activity may differ from one's actual ability; for example, studies have shown both overestimation (43$47 \%)$ and underestimation (36-37\%) of maximum walking distance $[46,47]$. The present study used outcome measures that required the participants to actually perform activities.

The choice of outcome measures for validation was primarily focused on stability in gait and standing activities, but also included anticipatory postural adjustment [13]. Since the $\mathrm{ABC}$ incorporates items related to reactive postural response (crowded shopping malls and being bumped into), tests measuring compensatory stepping could have been included. A fall could be regarded as the ultimate consequence of balance impairment, and hence as a perfect gold standard. Unfortunately, falls do not reflect less-pronounced balance problems which still may have a severe impact on everyday life.

Balance confidence is considered as a personal factor using the ICF model [48] while the TUG, TUG ${ }^{\mathrm{cog}}, 25 \mathrm{TW}$, FSST, DGI, and CST are measures at the level of activity. The use of assistive walking device is an environmental factor, facilitating activity and participation. The ICF model can be used to structure outcome measures and findings and their mutual relation. Future research within this area is warranted.

The $A B C$ was easily administered to the studied sample and took approximately 5 minutes to fill in. The standardized instructions of the questionnaires gave sufficient information to the participants, and the scales might as well have been filled in without the presence of trained personnel. The scales can be administered by any caregiver. The patient could also fill in the questionnaires at home and bring them to an appointment in clinical praxis, for time efficiency.

4.1. Study Limitations. The sample in the present study was restricted to PwMS interested in participating in balance exercise, which may have affected the generalizability. The sample is considered representative for type of MS, but the proportion of women was larger than that expected in the population. Even if more women than men are diagnosed with MS, the ratio in this study was $4: 1$. The sample was also restricted to include only those who still had the ability to walk at least $100 \mathrm{~m}$. A decision based upon the use of measures for testing convergent validity. Balance impairment is surely also an issue for those with more explicit walking limitation, and the results of the present or previous [28] study cannot be generalized to more severely disabled people (EDSS > 6). The use of self-rating scales may also be problematic for those with severe cognitive disability. Finally, 
another limitation is the reliance on retrospectively collected data on previous falls since a correlation between daily reported and retrospectively reported falls has been reported at $r=0.82$ [12].

\section{Conclusions}

Lack of balance confidence is present in many everyday activities for PwMS and should be taken into consideration along with the physical and environmental components. This study adds information of the validity of the $\mathrm{ABC}$ to measure balance confidence in PwMS. This study could not show any differences between men and women in balance confidence. The $\mathrm{ABC}$ did discriminate multiple fallers from non-fallers.

\section{Conflict of Interests}

The authors declare that there is conflict of interests.

\section{Acknowledgments}

Thanks are due to the assisting PTs: Anna Carling, Department of Physiotherapy at University Hospital, Örebro; Steven Allen, Brickegårdens Primary Health Care Centre; Anna Lövgren and Kerstin Eriksson, Nora Primary Health Care Centre; Malin Andreasson and Helena Vesterlin, NeuroRehab at Mälarhospital in Eskilstuna; Ingmarie Westlund and Ingrid Lundström, Rehabclinic at Västerås Hospital; Lena Sanner and Malin Nilsson, Rehabunit at the Central Hospital in Karlstad. This work was funded by the UppsalaÖrebro Regional Research Council, the Research Committee of Örebro County Council, and the Norrbacka-Eugenia Foundation.

\section{References}

[1] Swedish Multiple Sclerosis Registry, 2011, http://www.msreg .net/cms/sv/home.

[2] National Multiple Sclerosis Society, "FAQs about MS," 2012, http://www.nationalmssociety.org/about-multiple-sclerosis/ what-we-know-about-ms/faqs-about-ms/index.aspx\# whogets.

[3] D. McAlpine and W. B. Matthews, Eds., McAlpine's Multiple Sclerosis, Churchill Livingstone, Edinburgh, UK, 2nd edition, 1991.

[4] F. Soyuer, M. Mirza, and U. Erkorkmaz, "Balance performance in three forms of multiple sclerosis," Neurological Research, vol. 28, no. 5, pp. 555-562, 2006.

[5] M. H. Cameron and S. Lord, "Postural control in multiple sclerosis: implications for fall prevention," Current Neurology and Neuroscience Reports, vol. 10, no. 5, pp. 407-412, 2010.

[6] M. L. Corradini, S. Fioretti, T. Leo, and R. Piperno, "Early recognition of postural disorders in multiple sclerosis through movement analysis: a modeling study," IEEE Transactions on Biomedical Engineering, vol. 44, no. 11, pp. 1029-1038, 1997.

[7] G. M. Karst, D. M. Venema, T. G. Roehrs, and A. E. Tyler, "Center of pressure measures during standing tasks in minimally impaired persons with multiple sclerosis," Journal of Neurologic Physical Therapy, vol. 29, no. 4, pp. 170-180, 2005.
[8] A. Kalron, Z. Dvir, and A. Achiron, "Effect of a cognitive task on postural control in patients with a clinically isolated syndrome suggestive of multiple sclerosis," European Journal of Physical and Rehabilitation Medicine, vol. 47, no. 4, pp. 579586, 2011.

[9] D. Cattaneo, C. De Nuzzo, T. Fascia, M. Macalli, I. Pisoni, and R. Cardini, "Risks of falls in subjects with multiple sclerosis," Archives of Physical Medicine and Rehabilitation, vol. 83, no. 6, pp. 864-867, 2002.

[10] M. L. Finlayson, E. W. Peterson, and C. C. Cho, "Risk factors for falling among people aged 45 to 90 years with multiple sclerosis," Archives of Physical Medicine and Rehabilitation, vol. 87, no. 9, pp. 1274-1279, 2006.

[11] P. N. Matsuda, A. Shumway-Cook, A. M. Bamer, S. L. Johnson, D. Amtmann, and G. H. Kraft, "Falls in multiple sclerosis," $P M$ \& $R$, vol. 3, no. 7, pp. 624-632, 2011.

[12] Y. Nilsagård, C. Lundholm, E. Denison, and L. G. Gunnarsson, "Predicting accidental falls in people with multiple sclerosisa longitudinal study," Clinical Rehabilitation, vol. 23, no. 3, pp. 259-269, 2009.

[13] F. B. Horak, D. M. Wrisley, and J. Frank, "The balance evaluation systems test (BESTest) to differentiate balance deficits," Physical Therapy, vol. 89, no. 5, pp. 484-498, 2009.

[14] E. W. Peterson, C. C. Cho, and M. L. Finlayson, "Fear of falling and associated activity curtailment among middle aged and older adults with multiple sclerosis," Multiple Sclerosis, vol. 13, no. 9, pp. 1168-1175, 2007.

[15] E. W. Peterson, C. C. Cho, L. von Koch, and M. L. Finlayson, "Injurious falls among middle aged and older adults with multiple sclerosis," Archives of Physical Medicine and Rehabilitation, vol. 89, no. 6, pp. 1031-1037, 2008.

[16] M. E. Tinetti and L. Powell, "Fear of falling and low selfefficacy: a cause of dependence in elderly persons," Journals of Gerontology, vol. 48, pp. 35-38, 1993.

[17] A. Bandura, "Self-efficacy: toward a unifying theory of behavioral change," Psychological Review, vol. 84, no. 2, pp. 191-215, 1977.

[18] A. Bandura, "Self-efficacy mechanism in human agency," American Psychologist, vol. 37, no. 2, pp. 122-147, 1982.

[19] P. N. Matsuda, A. Shumway-Cook, M. A. Ciol, C. H. Bombardier, and D. A. Kartin, "Understanding falls in multiple sclerosis: association of mobility status, concerns about falling, and accumulated impairments," Physical Therapy, vol. 92, no. 3, pp. 407-415, 2012.

[20] Y. C. Learmonth, L. Paul, L. Miller, P. Mattison, and A. K. McFadyen, "The effects of a 12-week leisure centre-based, group exercise intervention for people moderately affected with multiple sclerosis: a randomized controlled pilot study," Clinical Rehabilitation, vol. 26, no. 7, pp. 579-593, 2012.

[21] M. E. Tinetti, D. Richman, and L. Powell, "Falls efficacy as a measure of fear of falling," Journals of Gerontology, vol. 45, no. 6, pp. P239-P243, 1990.

[22] N. M. Salbach, N. E. Mayo, J. A. Hanley, C. L. Richards, and S. Wood-Dauphinee, "Psychometric evaluation of the original and Canadian French version of the activities-specific balance confidence scale among people with stroke," Archives of Physical Medicine and Rehabilitation, vol. 87, no. 12, pp. 1597-1604, 2006.

[23] H. Karapolat, S. Eyigor, Y. Kirazli, N. Celebisoy, C. Bilgen, and T. Kirazli, "Reliability, validity, and sensitivity to change of Turkish Activities-specific Balance Confidence Scale in patients with unilateral peripheral vestibular disease," International Journal of Rehabilitation Research, vol. 33, no. 1, pp. 12-18, 2010. 
[24] N. Schott, "German adaptation of the "Activities-specific Balance Confidence (ABC) scale" for the assessment of fallsrelated self-efficacy," Zeitschrift fur Gerontologie und Geriatrie, vol. 41, no. 6, pp. 475-485, 2008.

[25] M. J. van Heuvelen, J. Hochstenbach, M. H. de Greef, W. H. Brouwer, T. Mulder, and E. Scherder, "Is the Activities-specific Balance Confidence scale suitable for Dutch older persons living in the community?" Tijdschrift voor Gerontologie en Geriatrie, vol. 36, no. 4, pp. 146-154, 2005.

[26] Q. Guan, H. Han, Y. Li, L. Zhao, L. Jin, and Q. Zhan, "Activities-specific Balance Confidence (ABC) Scale adapted for the mainland population of China," Clinical Rehabilitation, vol. 26, no. 7, pp. 648-655, 2011.

[27] U. Dalgas, E. Stenager, and T. Ingemann-Hansen, "Multiple sclerosis and physical exercise: recommendations for the application of resistance-, endurance- and combined training," Multiple Sclerosis, vol. 14, no. 1, pp. 35-53, 2008.

[28] D. Cattaneo, A. Regola, and M. Meotti, "Validity of six balance disorders scales in persons with multiple sclerosis," Disability and Rehabilitation, vol. 28, no. 12, pp. 789-795, 2006.

[29] S. A. Arnadottir, L. Lundin-Olsson, E. D. Gunnarsdottir, and A. G. Fisher, "Application of Rasch analysis to examine psychometric aspects of the activities-specific balance confidence scale when used in a new cultural context," Archives of Physical Medicine and Rehabilitation, vol. 91, no. 1, pp. 156-163, 2010.

[30] Y. Nilsagård and A. Forsberg, "Psychometric properties of the Activities-Specific Balance Confidence Scale in persons 0-14 days and 3 months post stroke," Disability and Rehabilitation, vol. 34, no. 14, pp. 1186-1191, 2011.

[31] A. M. Myers, P. C. Fletcher, A. H. Myers, and W. Sherk, "Discriminative and evaluative properties of the activities-specific balance confidence (ABC) scale," Journals of Gerontology A, vol. 53, no. 4, pp. M287-M294, 1998.

[32] A. M. Myers, L. E. Powell, B. E. Maki, P. J. Holliday, L. R. Brawley, and W. Sherk, "Psychological indicators of balance confidence: relationship to actual and perceived abilities," Journals of Gerontology A, vol. 51, no. 1, pp. M37-M43, 1996.

[33] C. H. Polman, S. C. Reingold, B. Banwell et al., "Diagnostic criteria for multiple sclerosis: 2010 revisions to the McDonald criteria," Annals of Neurology, vol. 69, no. 2, pp. 292-302, 2011.

[34] Y. E. Nilsagård, A. S. Forsberg, and L. von Koch, "Balance exercise for persons with multiple sclerosis using Wii games: a randomised,controlled multi-centre study," Multiple Sclerosis. In press.

[35] L. E. Powell and A. M. Myers, "The Activities-specific Balance Confidence (ABC) Scale," Journals of Gerontology A, vol. 50, no. 1, pp. M28-M34, 1995.

[36] A. Shumway-Cook and M. H. Woollacott, Motor Control: Theory and Practical Applications, Williams \& Wilkins, Baltimore, Md, USA, 1995.

[37] D. Podsiadlo and S. Richardson, "The timed "Up \& Go": a test of basic functional mobility for frail elderly persons," Journal of the American Geriatrics Society, vol. 39, no. 2, pp. 142-148, 1991.

[38] Y. Nilsagard, C. Lundholm, L. G. Gunnarsson, and E. Dcnison, "Clinical relevance using timed walk tests and 'timed up and go' testing in persons with multiple sclerosis," Physiotherapy Research International, vol. 12, no. 2, pp. 105-114, 2007.

[39] A. Shumway-Cook, S. Brauer, and M. Woollacott, "Predicting the probability for falls in community-dwelling older adults using the timed up and go test," Physical Therapy, vol. 80, no. 9, pp. 896-903, 2000.

[40] G. R. Cutter, M. L. Baier, R. A. Rudick et al., "Development of a multiple sclerosis functional composite as a clinical trial outcome measure," Brain, vol. 122, no. 5, pp. 871-882, 1999.
[41] J. A. Cohen, G. R. Cutter, J. S. Fischer et al., "Use of the multiple sclerosis functional composite as an outcome measure in a phase 3 clinical trial," Archives of Neurology, vol. 58, no. 6, pp. 961-967, 2001.

[42] A. Solari, D. Radice, L. Manneschi, L. Motti, and E. Montanari, "The multiple sclerosis functional composite: different practice effects in the three test components," Journal of the Neurological Sciences, vol. 228, no. 1, pp. 71-74, 2005.

[43] J. McConvey and S. E. Bennett, "Reliability of the dynamic gait index in individuals with multiple sclerosis," Archives of Physical Medicine and Rehabilitation, vol. 86, no. 1, pp. 130133, 2005.

[44] W. Dite and V. A. Temple, "A clinical test of stepping and change of direction to identify multiple falling older adults," Archives of Physical Medicine and Rehabilitation, vol. 83, no. 11, pp. 1566-1571, 2002.

[45] C. Y. Wang, C. J. Yeh, and M. H. Hu, "Mobility-related performance tests to predict mobility disability at 2-year follow-up in community-dwelling older adults," Archives of Gerontology and Geriatrics, vol. 52, no. 1, pp. 1-4, 2011.

[46] A. Créange, I. Serre, M. Levasseur et al., "Walking capacities in multiple sclerosis measured by global positioning system odometer," Multiple Sclerosis, vol. 13, no. 2, pp. 220-223, 2007.

[47] I. Ringel and U. K. Zettl, "Estimates of the walking distance in multiple sclerosis patients and their effect on the EDSS," Journal of Neurology, vol. 253, no. 5, pp. 666-667, 2006.

[48] World Health Organization, International Classification of Functioning, Disability and Health (ICF), World Health Organization, Geneva, Switzerland, 2001. 


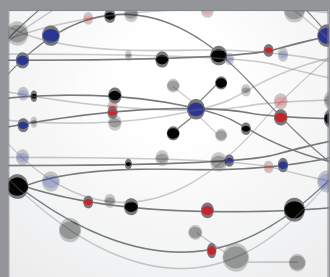

The Scientific World Journal
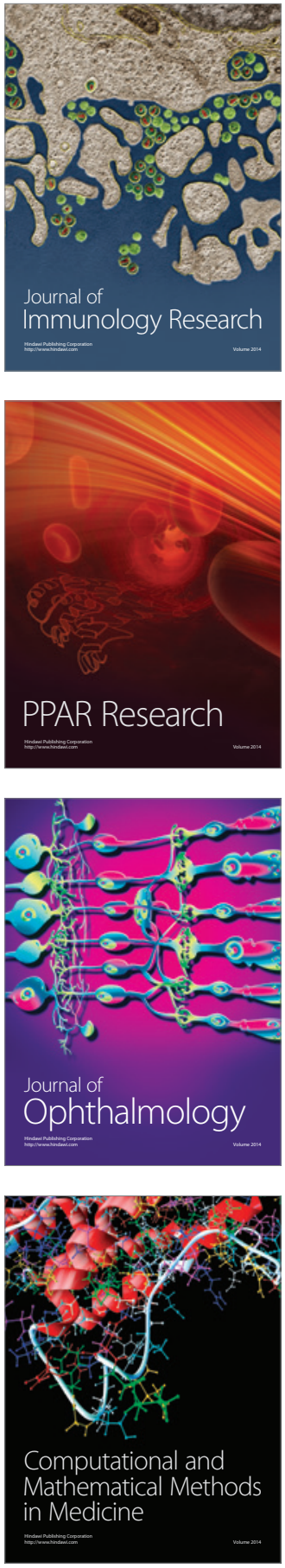

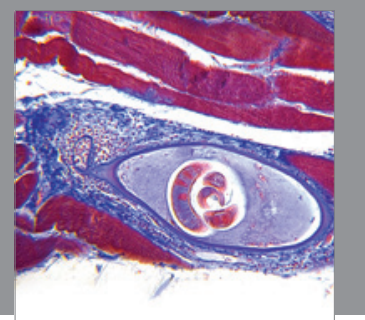

Gastroenterology

Research and Practice
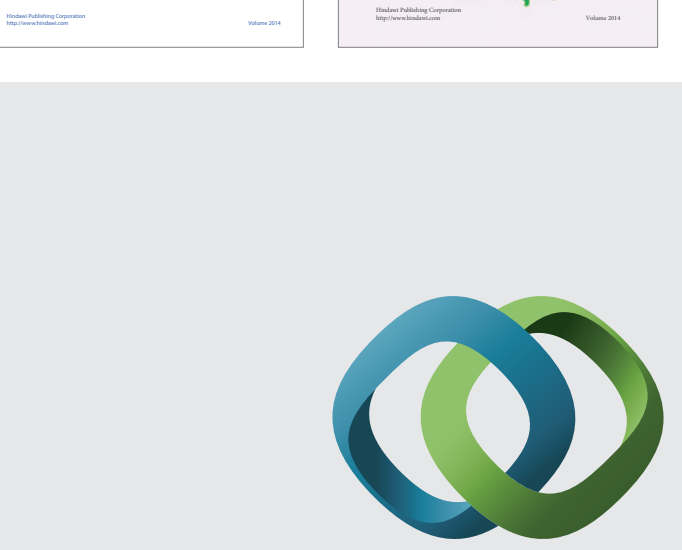

\section{Hindawi}

Submit your manuscripts at

http://www.hindawi.com
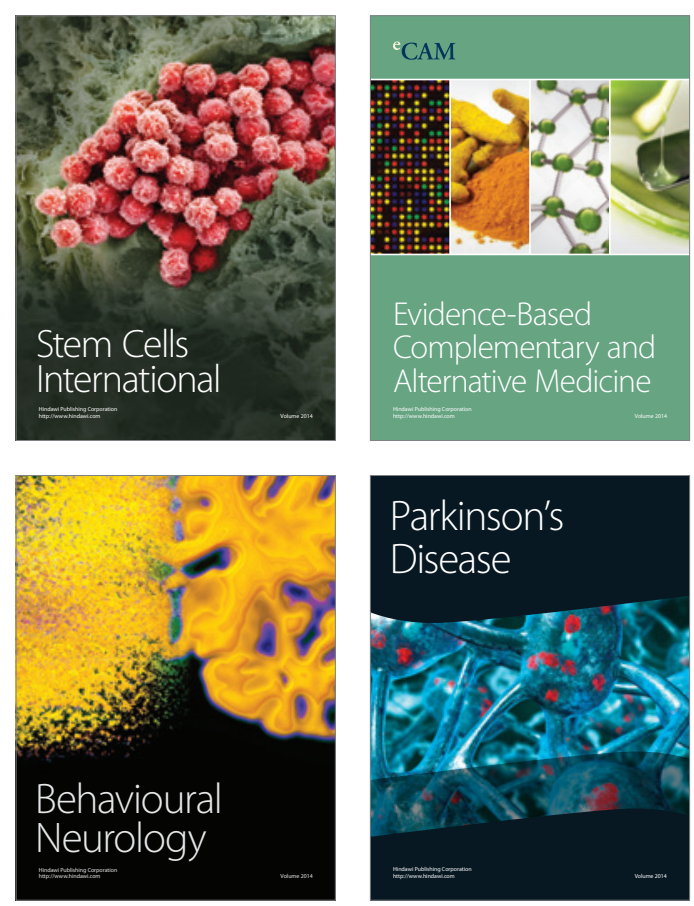

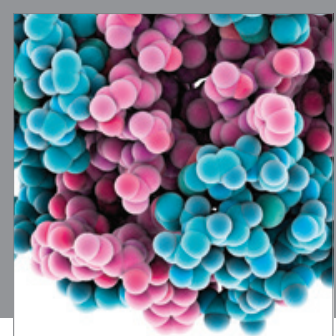

Journal of
Diabetes Research

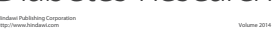

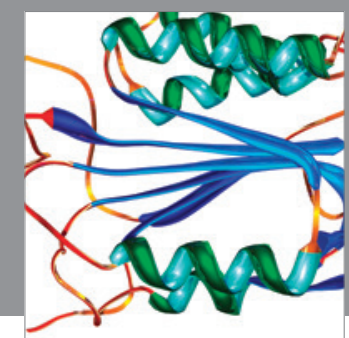

Disease Markers
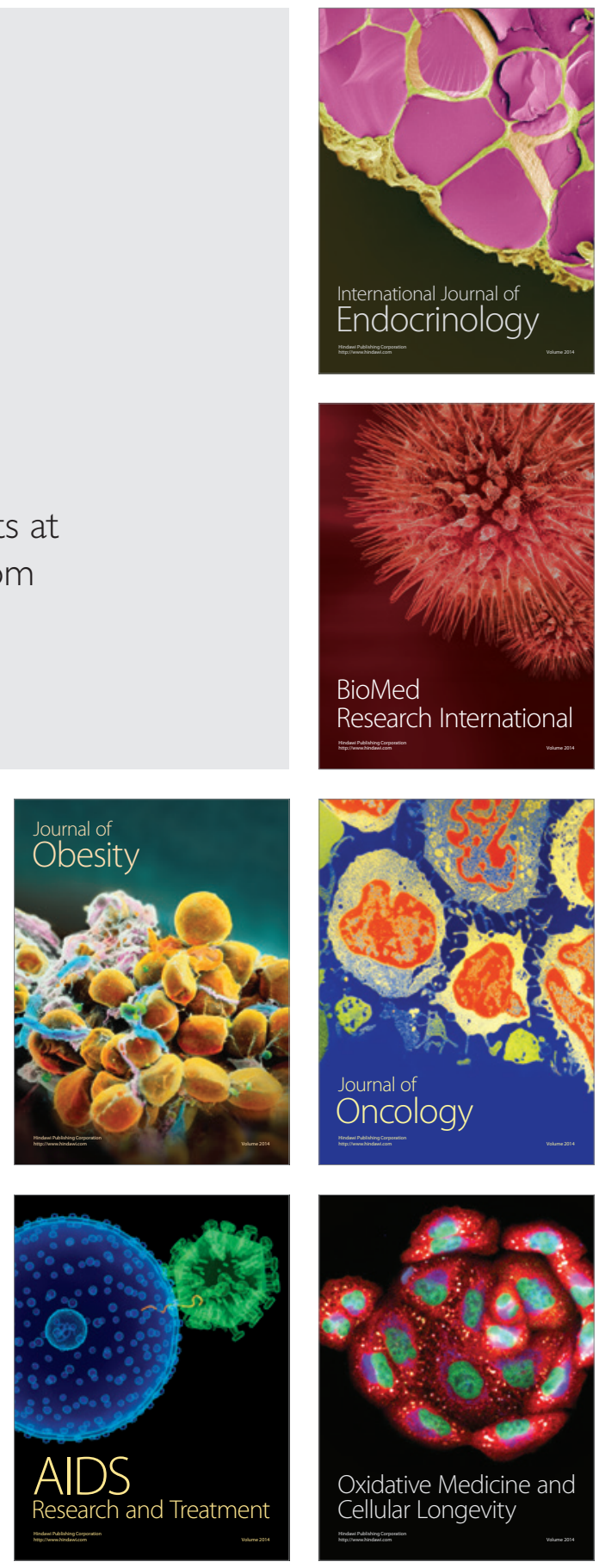